\title{
Flood Plain Mapping and Hazard Assessment of Muga River by Using ArcGIS and HEC-RAS Model Upper Blue Nile Ethiopia
}

\author{
Solomon Bogale Aynalem \\ Department of Hydraulic and Water Resources Engineering, Debre Markos University, Debre Markos, Ethiopia
}

\section{Email address:}

solomonbogale89@gmail.com

\section{To cite this article:}

Solomon Bogale Aynalem. Flood Plain Mapping and Hazard Assessment of Muga River by Using ArcGIS and HEC-RAS Model Upper Blue Nile Ethiopia. Landscape Architecture and Regional Planning. Vol. 5, No. 4, 2020, pp. 74-85. doi: 10.11648/j.larp.20200504.13

Received: September 16, 2020; Accepted: September 29, 2020; Published: November 23, 2020

\begin{abstract}
Flood happens repeatedly and is a common phenomenon in Ethiopia causing a lot of losses to human lives as well as damage to property. The majority of flood disasters' victims are people living in and nearby stretch of floodplains. It results direct or indirect loss of agricultural productivity, infrastructure, and disruption of transportation access and services. The objective of this study was to analyze flood inundation area mapping and Hazard Assessment of Muga River. Flood generating factors, i.e. slope, elevation, rainfall, drainage density, land use, and soil type were rated and combined to delineate flood hazard zones using a multi-criteria evaluation technique in an ArcGIS environment. The flooded areas along the Muga River have been mapped based on highest flows for different return periods using the HEC-RAS model, ArcGIS for spatial data processing and HEC-GeoRAS for interfacing between HEC-RAS and ArcGIS. The areas along the Muga River simulated to be inundated for 5, 10, 25, 50 and 100 years return periods. The flooded areas along the Muga River are $18 \mathrm{~km} 2,21 \mathrm{~km}^{2}, 26 \mathrm{~km}^{2}, 34 \mathrm{~km}^{2}$ and $43 \mathrm{~km}^{2}$ for $5,10,25$, 50 and 100 year return periods, respectively. Proper land use management and afforestation, is significant to reduce the adverse effects of flooding particularly in the low-lying flood prone areas. The result of this study will helps the concerned bodies to formulate develop strategies according to the available flood plain mapping and hazard to the area.
\end{abstract}

Keywords: Muga River, ArcGIS, HEC_RAS, HEC_GeoRAS

\section{Introduction}

Flood defines as high flow that exceeds or over top of the capacity either the natural or the artificial bank of the stream or the river channel [1]. Since excessive rain on the land, streams overflowing channels or unexpected high tides or tsunamis wave in a coastal area. Some of the most important factors that determine the feature of floods are precipitation event characteristics, depth of flood, flow velocity and duration of precipitation [2].

Floods can be also explained as excess flows exceeding the transporting capacity of river channel, lakes, ponds, reservoirs, drainage system, dam and any other water bodies, whereby water inundates outside water bodies areas (Baker, [3]. Flood is a continuous natural and reoccurring event in floodplains of rainfall areas like Ethiopia, where over $80 \%$ of annual precipitation falls in the four wet months [4]. The flooding can be caused by, for instance, heavy rain, snow melt, land subsidence, rising of groundwater, dam failures. Moreover, since the industrial revolution, climate change has been clearly influencing many environmental and social sectors; in particular, it has been showing significant impact on water resources.

An inundation map displays the spatial extent of probable flooding for different scenarios and can be present either in quantitative or qualitative ways [5]. The hazard assessment is to identify the probability of occurrence of a specific hazard, in a specific future time, as well as its intensity and area of impact [6]. Hazard is a potentially damaging physical event, phenomenon that may cause the loss of life or injury, property damage, environmental degradation, social and economic disruption. Hazards can include latent conditions that may represent future threats and can have different origins: natural (geological, hydro meteorological and biological) or induced by human processes (environmental degradation and technological hazards [7]. Hazards can be 
single, sequential or combined in their origin and effects [8]. Each hazard is characterized by its location, intensity, and probability. The flood hazard assessment need to be presented using a simple classification as simple as possible, such as indicating very high, high, medium, low, or very low hazard. The later means no danger [9]. The inundation or hazard assessment mapping delineates flood hazard areas in the river basin by integrating local knowledge, hydrological, meteorological, and geomorphologic data using different approaches. The final flood hazard feature requires large local or field knowledge inclusion in the model. The inundation or hazard mapping is an essential component of emergency action plans; it supports policy and decision makers to decide about how to allocate resources, flood forecasting, ecological studies, and significant land use planning in flood prone areas [10]. The excess flows in water bodies can happen due to several factors, but seasonal heavy rainfall is the main cause of flooding in the Muga River [11]. The problem of river flooding due to excess rainfall in short time and the following high river discharge is a great concern in the Muga River. In the main rainy season (June, July, August, and September); the floodplain of the Muga River extends to particular areas that are not normally covered with water. The intense rainfall in the highlands of the Muga River causes flooding at its downstream and damages settlements close to any section of the river [12].

The Muga River has been flooded for short durations after intense or prolonged rainfall events, but the downstream area has been flooded for weeks or months every year during the wet season [13]. The timing and size of the flood will influence the production of the crops cultivated in the floodplain. If the intense rainfall in the Muga River will occur at the end of rainy season, the floods can damage the crops. The floods are becoming highly unpredictable in many ways [14]. Flooding is becoming a big concern in the Muga River due to crop damage and human welfare losses, so that GIS based flood hazard assessment and extent mapping is crucial. There is a need for flood regulation, timely forecasting and hazard extent mapping in the Muga River. Some literatures suggest that the frequency and magnitude of river flood might increase due to climate change [15]. In the last decade, the frequency of flash floods markedly increased all over Ethiopia, which caused a number of fatalities and large property damage [16]. They, concluded that the whole country is potentially prone to the flash floods hazard and these may be associated with climate change, intense monsoon rainfall in short time during the main rainy season $[16,17]$. The main objective of this study is to analyze the inundation area along the Muga River network, and to assess the flood hazard in the whole Muga River by integrating geomorphic, topographic, and hydrological data using ArcGIS with HEC-GeoRAS/HEC-RAS model. Specifically, the study aims to identify the inundated area along the river basin with a particular return period of $5,10,25,50$ and 100 years period and to identify the most flood prone areas of the basin.

\section{Materials and Methods}

\subsection{Description of Study Area}

Muga watershed (study area) is found in Upper Blue Nile Basin, which is about $248 \mathrm{~km}$ far from North West of Addis Ababa between the towns of Dejen and Bichena. It covers an area of $706.81 \mathrm{~km}^{2}$. This area is one of the choke mountain watershed which is located in the Northern highlands of Ethiopia, within $10^{\circ} 6^{\prime} 30^{\prime \prime}$ North to $10^{\circ} 43^{\prime} 30^{\prime}$ 'North and $37^{\circ} 49^{\prime} 00^{\prime \prime}$ 'East to $38^{\circ} 16^{\prime} 30^{\prime \prime}$ 'East. Muga River originates from Bibugn district near Choke Mountain at elevation of 4084 m.a.s.l and drains to Abbay River. The agro-climatic zone of Muga is wet/moist dega (temperate like climate-highlands with 2500-3000 meters altitude) and kola (hot and arid type, less than $1500 \mathrm{~m}$ in altitude) when it reaches to Blue Nile River.

The Woredas included in the Muga watershed are Debay Telagen in the upstream, Enemay woreda in the middle and Dejen Woreda in the downstream side. In the watershed Muga is the main river which is a perennial river and Yegudfin is a tributary of Muga, which contributes flow only during the rainy season. Since the flow of the river is increased from upstream to downstream, the channels of the downstream are inundated by flood. The location of the study area is shown in figure 1 .

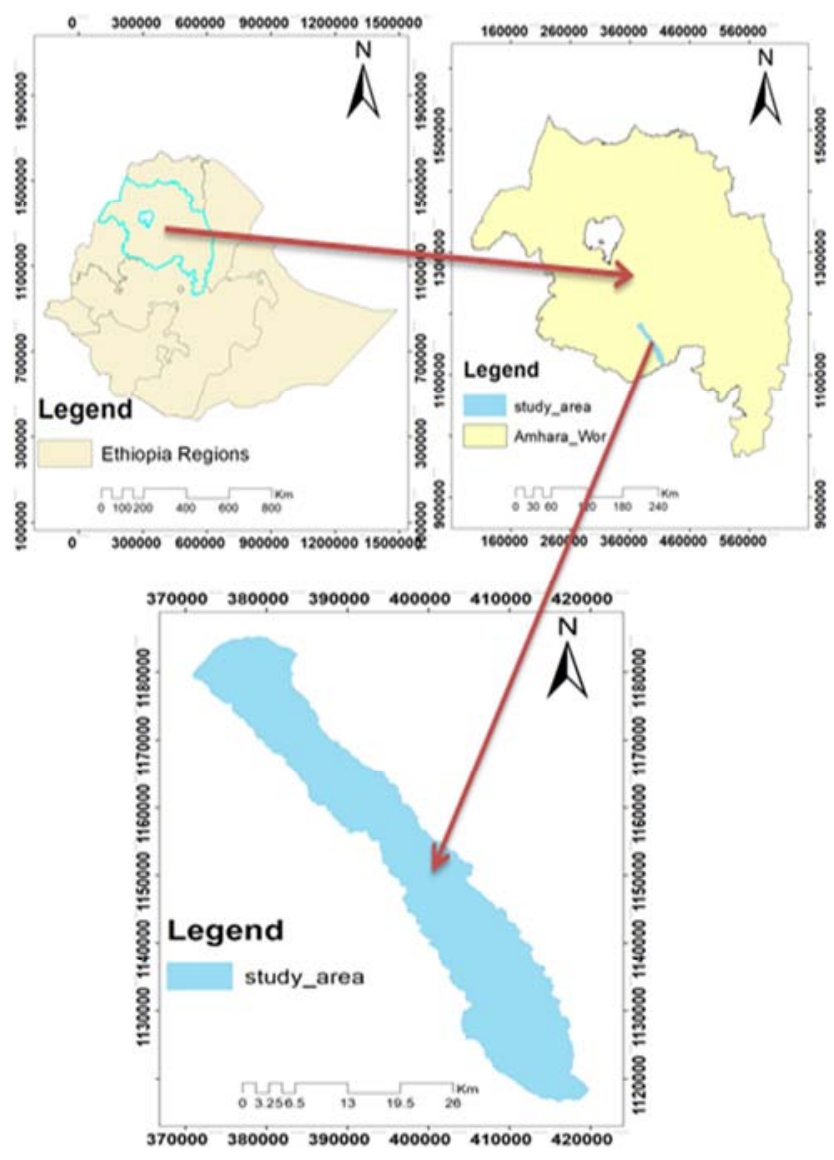

Figure 1. Location Map of the Study Area.

\subsection{Soil types and Geology}

The regional geology of the Muga watershed is dominated 
by the Tertiary volcanic rock and Quaternary Basalts. In this watershed seven main soil types are found which include, are Vertisols, Cambisols, Lithosols, Luvisols, Nitosols, Rendziains and Rock Surfaces figure 2. Generally, the soils types of this watershed area are characterized with shallow, moderate to deep and very deep in depth and sandy clay to clay texture types. The erodibility of these soils also varies from medium to very erodible characteristics.

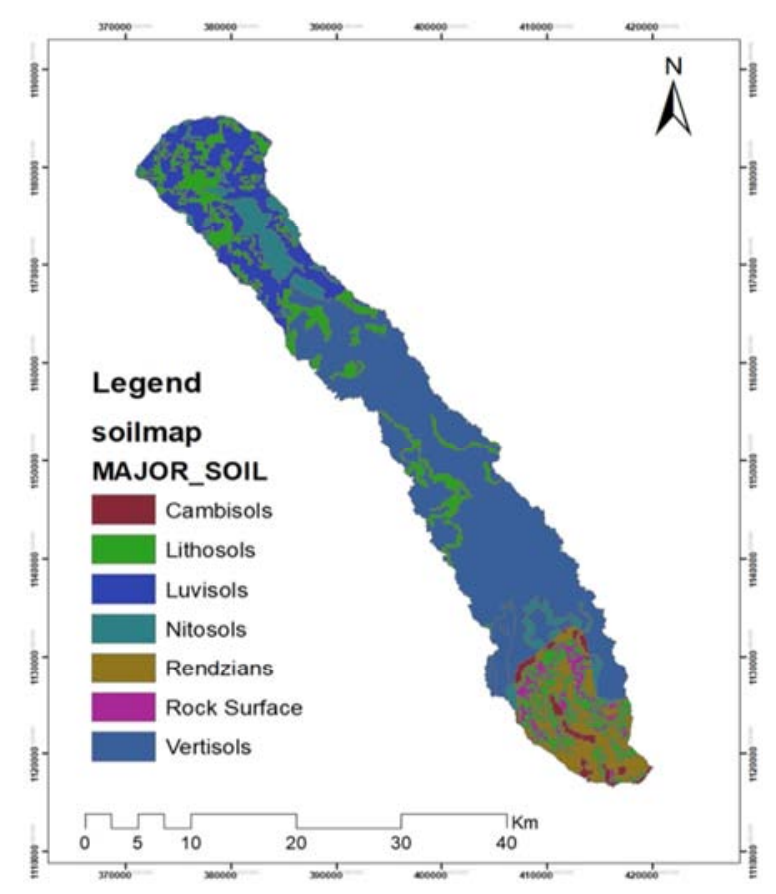

Figure 2. Map of the soil types of Muga watershed.

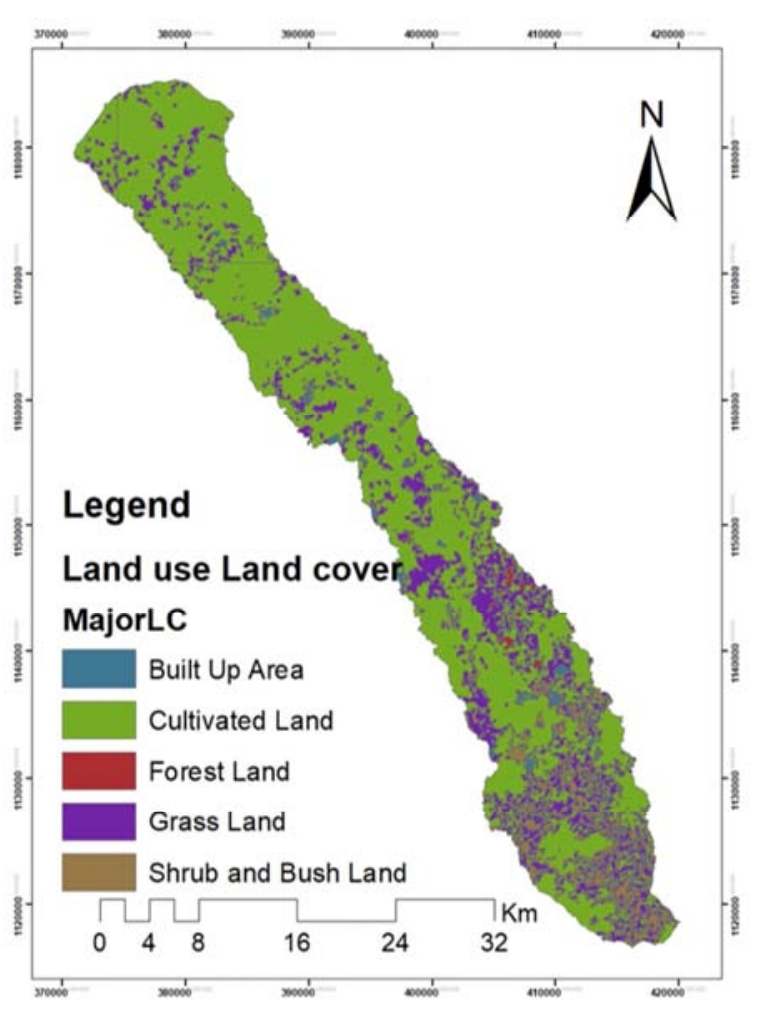

Figure 3. Land Use/Land Cover Map of Muga watershed.

\subsection{Land Use and Land Cover}

The land use is one of the most important factors that affect runoff, evapotranspiration and surface erosion in a catchment. The land use land cover data combined with the soil cover data generates the hydrologic characteristics of the basin or the study area, which in turn determines the excess precipitation, recharge to the groundwater system and the storage in the soil layers. In the watershed, there are five land use/land cover types such as cultivated land, shrub and bush land, grass land, forest land and built up area figure 3 . Among these types, cultivated land is the dominant one in the watershed that covers most of the land area.

\subsection{Meteorological Data Collection and Analysis}

Meteorological data collection of the area is one of the basic requirements of any water resource management and flood frequency analysis. The meteorological data, such as rainfall and maximum and minimum temperature of different record length that is used for this study were collected from the National Meteorological Agency (NMA). Before using the data for further analysis, it is important to make sure that data are homogenous, correct, sufficient, and filling of the missing values.

\subsection{Hydrological Data Collection and Analysis}

The daily discharge of Muga River is collected from the Ministry of Water and Energy Bureau. Unlike the daily precipitation, the daily discharge has full data composition for the considered stations to represent the study area. The discharge gage is located at the outlet of Muga River downside of the access road from Dejen to Abay River. The stream flow data is processed according to model input criteria's and used as an input for HEC-HMS for calibration and validation and using for HEC-RAS models of the model result.

\subsection{Flood Hazard Assessment and Inundation Area Mapping}

The HEC-GeoRAS floodplain mapping hydraulics model has been used based on the simulated peak flow data from gauging station [18]. The DEM and other important components of flood hazard and inundation extent mapping have been analyzed using ArcGIS and HEC-GeoRAS. The most commonly used and selected flood generating factors, such as drainage density, digital elevation model, land use, soil type, rainfall, and slope were combined for flood hazard assessment using ArcGIS 10.4 [19]. The selected flood generating factors, such as average annual rainfall, soil map, elevation, slope, drainage density, and land use were rasterized and classified in raster format and then weighted overlay using ArcGIS 10.4 to generate the final flood hazard map [20].

The DEM (digital elevation model) was processed to create the TIN (triangular irregular network). After that, the river cross-sections, stream centerline, stream bank lines, flow lines, and other river geometry information were extracted from the 
TIN for the HEC-GeoRAS model. At the same time, the land use was processed to get the Manning's $n$ value for the individual cross-sections [21]. After the RAS geometry data preparation, the HEC-GeoRAS model was used to generate the RAS GIS import file (final river geometry file) that can be used as input for HEC-RAS Figure 4.

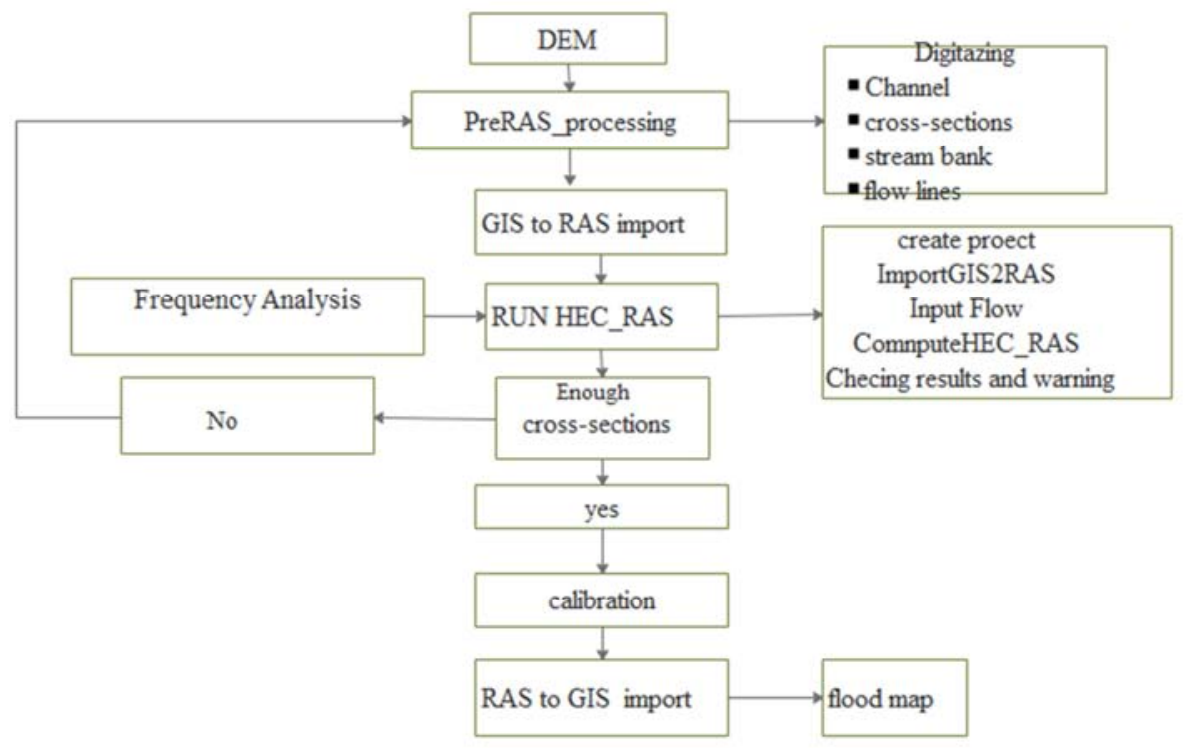

Figure 4. Flow chart of flood Plain and Inundation area mapping.

Checking the cross-section; editing the river geometry, and making final correction of the river geometry file in the HECRAS model. After the compilation of the final river geometry file, in different return periods and the HEC-RAS generated water level for different return periods [22]. The water surface level for each return period has been exported in HEC-GeoRAS for final inundation area mapping along the river [23]. Flood hazard assessments are slope, elevation, average rainfall, drainage density, land use, and soil type figure 5.

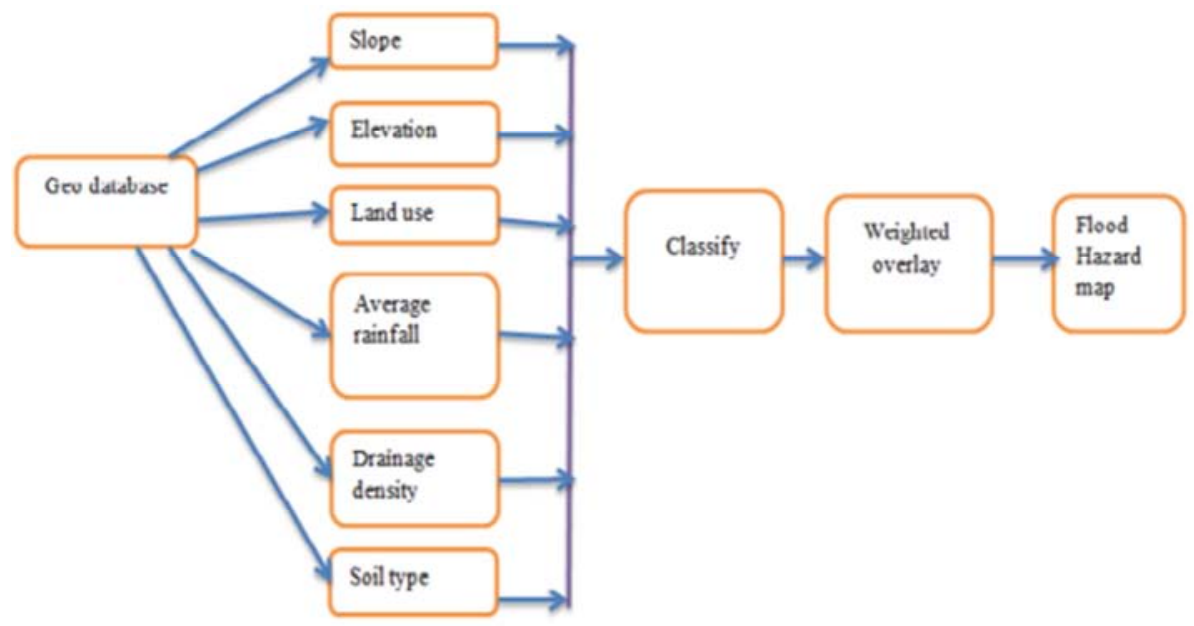

Figure 5. Computing the flood hazard map.

\subsection{General HEC-GeoRAS or HEC-RAS Model Description}

The Hydrologic Engineering Center's Geographical River Analysis System or HEC-RAS has been developed by US Army Corps of Engineers Hydrologic Engineering Center and it is a free downloadable with other supportive documents about how to use the model for flooded area mapping. The HEC-GeoRAS is a GIS extension with a set of procedures, tools, and utilities for the preparation of river geometry GIS data to import into HEC-RAS and it is used to generate the final inundation map [24]. The input data required for the River geometry preparation using the HECGeoRAS model are Triangular Irregular Network (TIN), DEM, and land use. The river geometry file and stream flow data are the input files for HEC-RAS to generate the water surface level along the River. The HEC-GeoRAS or HECRAS has been used worldwide for inundation mapping, such as in [25].

HEC-GeoRAS is a data management interface between 
ArcGIS and HEC-RAS. This tool provides or creates the river geometric file to be analyzed in HEC-RAS model. The river stream centerline, bank lines, flow path centerlines, and XS cut lines should be digitized from a previous river file, aerial photographs, or topographical datasets using HEC-GeoRAS interface. The river reach (river segment between junctions), cross-section and other related data are stored in the geo database file of HEC-GeoRAS [26]. The river and cross-section data layers are created with predefined attribute tables that are manually populated in the case of the river and reach names, while all other attributes are automatically calculated by the HEC-GeoRAS [23]. The interface extracts the geometric data in an.xml format that is imported into HEC-RAS. The results of the HEC-RAS model simulation will be entered into a GIS environment and further analyses will be performed using HECGeoRAS tool. The GIS data exchanged between HEC-RAS and ArcGIS are in sdf file format [27].

It is possible to edit the exported GIS geometric data in the HEC-RAS model using the HEC-RAS editor tools. The HEC-RAS consists of a number of editors' tools to deal with different functions in the modeling process. For this study only the geometric, steady flow data, cross-section, and steady flow simulation editors are used. The.xml file exported from the HEC-GeoRAS is imported into the Geometric Editor, which is a Graphical User Interface (GUI) that is used to manage the geographic data [28]. In this editor, the Manning friction values are entered for the cross-sections of each reach. The stream flow data is entered into the steady flow data editor. This editor extracts the river and data for the reaches from the geometric editor [29]. To compute the water

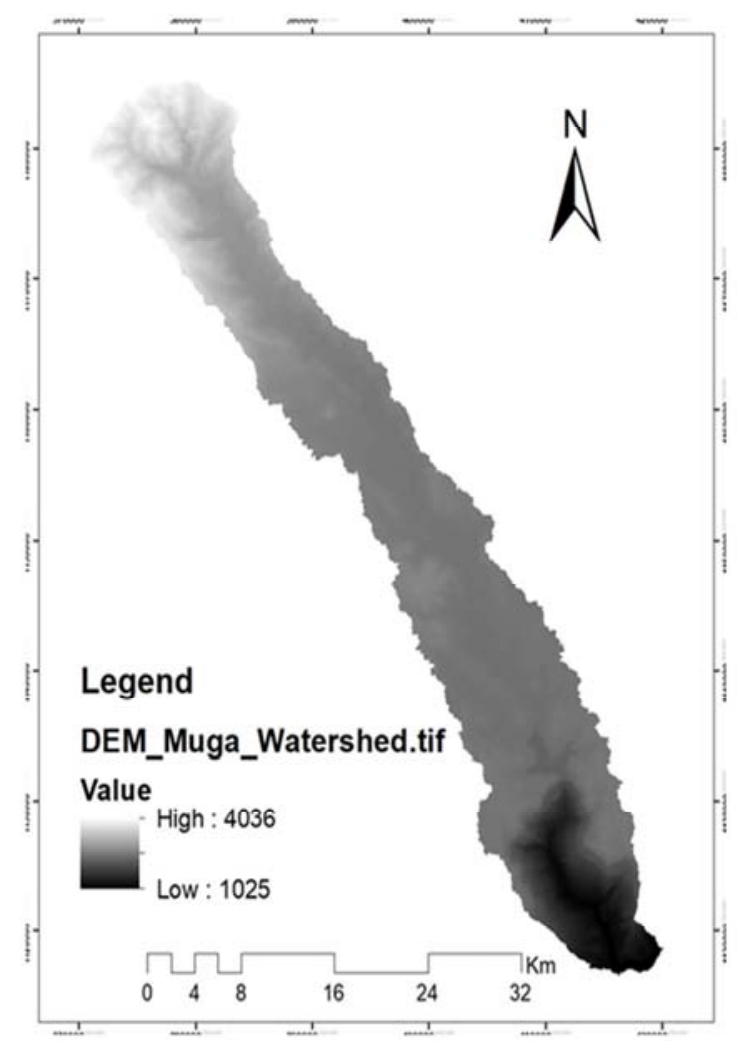

Figure 6. DEM and Triangulated Irregular Network of Muga Watershed. surface level, the model needs to know the starting water level at the start and end of reaches that are not connected and at junctions to other reaches (boundary conditions). For a steady flow analysis, four types of boundary conditions are available, namely known water surface level, critical depth, normal depth, and rating curve [30]. The critical depth option was selected in this study; the model will calculate the critical flow depth for the first cross-section along a reach from the cross-section profile and water volumes from the first two cross-sections using the Froude formula [31]. The steady flow water surface profiles module is used for calculating water surface profiles for steady, gradually varying flow using supercritical, subcritical and mixed flow regimes [32]. The model solves an energy loss equation between two cross-sections using friction and contract/expansion coefficients [19]. The output data of HEC-RAS model are water surface profile variations for different flow rates with varied recurrence intervals in desired lengths of the river, current velocity values, normal depth, critical depth, and hydraulic properties and parameters in the river [33]. The HEC-GeoRAS assists the ArcGIS in providing pre-processing, direct support, and post-processing functionality before and after the hydraulic analysis. For preprocessing, both HEC-GeoRAS and ArcGIS packages should preprocess data, but HEC-GeoRAS provides the extra capability to capture the geometric data according to the HEC-RAS format required for the hydraulic modeling. The HEC-GeoRAS exports and imports the spatial data to different formats between ArcGIS and HEC-RAS by using a data exchange format called a RAS GIS File [27]

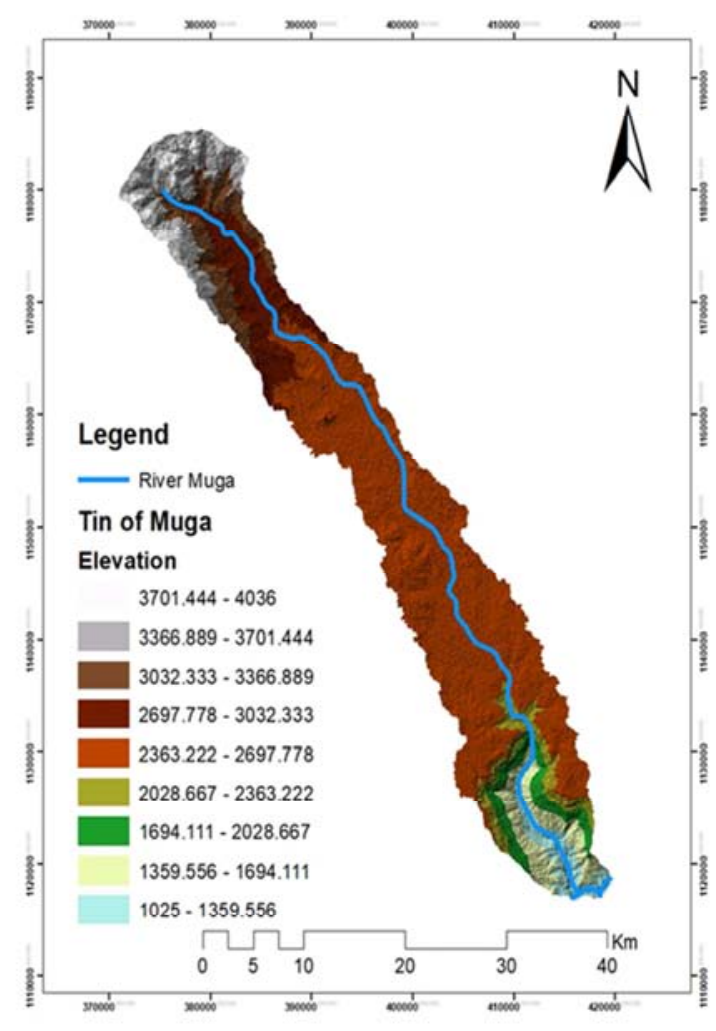




\subsection{Floodplain HEC-GeoRAS/HEC-RAS Data Analysis}

The ArcGIS extension of HEC-GeoRAS was used to extract the complete geometric datasets of the river from TIN for the HEC-RAS input figure 6. There are several rules and procedures in the HEC-GeoRAS/HEC-RAS manual regarding how to digitize or create the river geometry components. For example, the cross section lines must be drawn from the left bank to the right bank looking downstream, the cross section lines should be perpendicular to the flow direction, should not intersect, and should

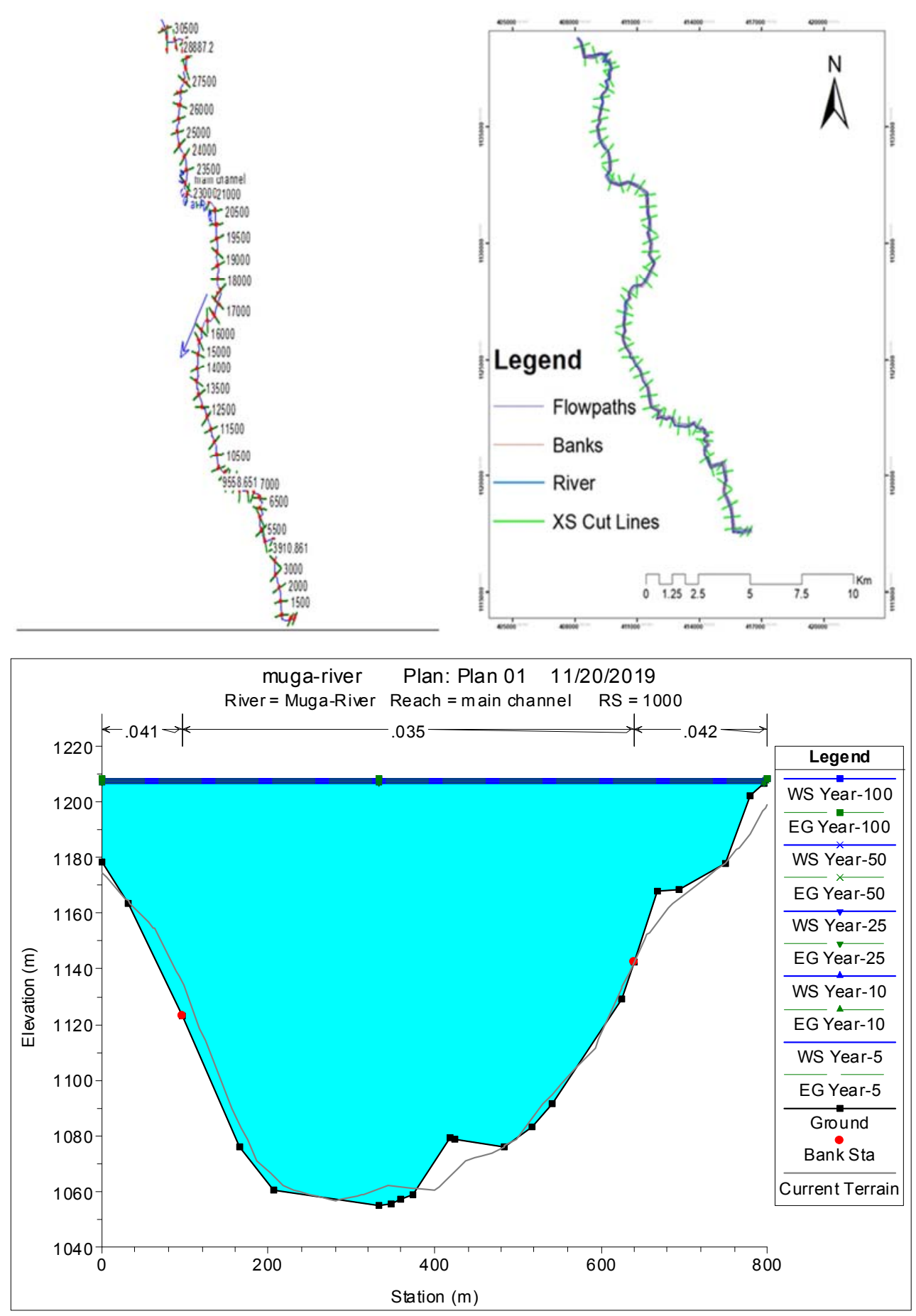

intersect the centerline. of flooded areas.

The HEC-RAS has the ability to import 3D River schematic and cross section data created in the GIS extension of the HEC-GeoRAS. Whereas, the HEC-RAS model only utilizes $2 \mathrm{D}$ data during the computations, the $3 \mathrm{D}$ information is used in the program for visualization purposes figure 7. During the field survey in this study, some GPS coordinate points were collected river basin to validate the spatial extent 


\subsection{Flood Hazard Factor Analysis}

The major flood generating factors used for flood hazard assessment are slope, elevation, average rainfall, drainage density, land use, and soil type. The DEM was converted into slope and elevation raster layers using the ArcGIS conversion tool. The lower the slope value is the flatter the terrain and in the same way the higher the slope value is the steeper the terrain. Based on their susceptibility to flooding; slope and

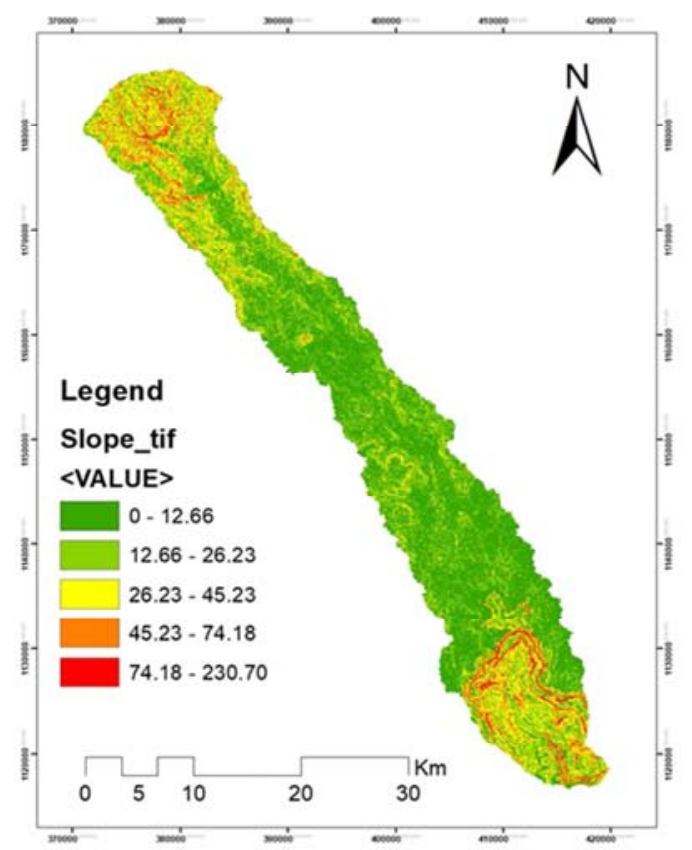

Figure 8. Susceptibility to flooding (rating of slope and elevation).
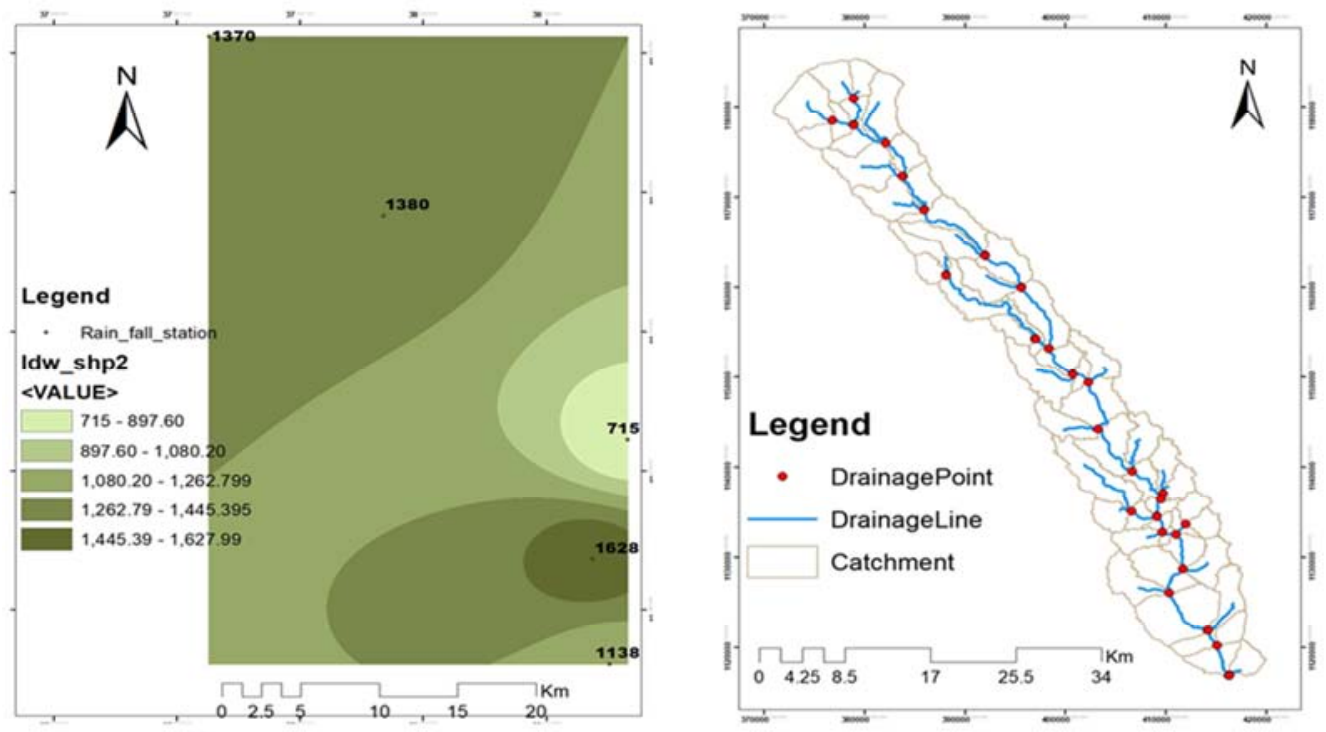

Figure 9. Susceptibility to flooding (rating of drainage density and rainfall).

The long-year mean rainfall pattern indicated that there is high precipitation in the west highlands peripheries, while there is low rainfall in the lowlands of the river basin figure 9 . In the classification process an area with higher rainfall, is

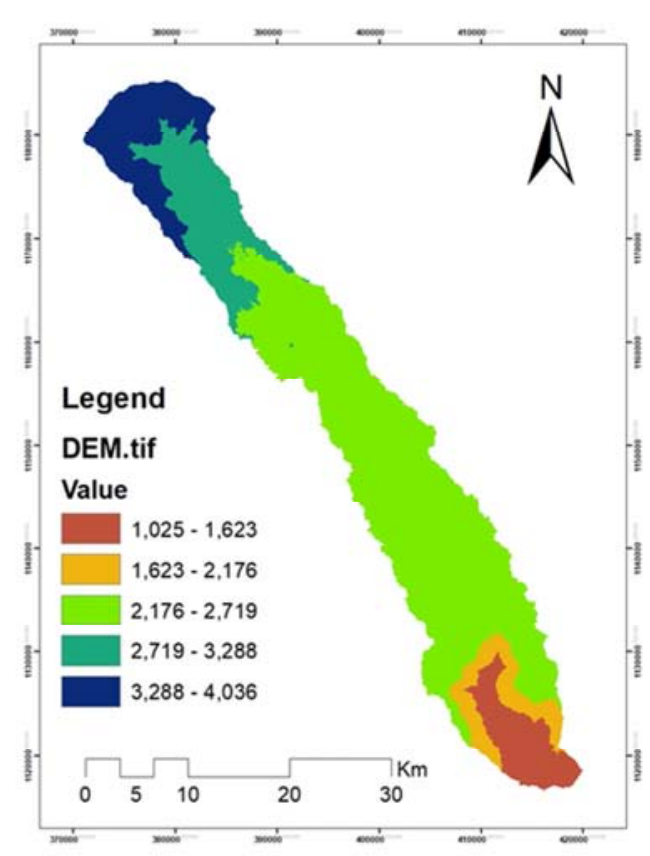

elevation have been classified into five classes. In the classification process, an area at the lowest elevation and slope, very highly affected by flood which is less than 1623 $\mathrm{m}$ and $<12.66 \%$, respectively figure 8 . Different breaking values were checked based on the expert knowledge, local information and the possible realization, was selected for slope and elevation hazard map. 
streams and rivers in a drainage basin divided by the total area of the drainage basin. The line density module calculates a magnitude per unit area from polyline features that fall within a radius around each cell. The drainage density layer was classified in classes. In the classification process an area with a higher drainage density is very highly affected by flood.

Although there is a wide range of soil types, five main soil classes were distinguished based on the hydrologic soil grouping system. These, five groups of soil types were converted into raster and reclassified based on the flood generating capacity that has a very high capacity to generate a very high flood rate figure 2 . The land use of the study area was classified into main classes and converted into a raster layer. Based on the flood generating characteristics of the land use type, cultivated land was assigned as very high flooding as shown in figure 3.

\section{Result and Discussion}

\subsection{HEC-RAS Model Calibration}

Model predictions of inundation flood extent are compared with the observed data using the random observation points in floodplain, approximately near the marginal parts of the flooded area. The point information observed using GPS in the field along the Muga River reach. Interview with local people, witness and land owners has conducted during field survey in addition to observing marks of flood levels and maximum flood estimation technique by tracing the high flood level of a drainage area using local elder's information and looking river transported debris over the river bank to make sure about observation points. Silt lines on the outcrop rocks, vegetation, litter debris and sand and silt deposits used as the stage indicators of the flood in the study reach [34]. These points were later processed through ESRI ArcView to overlay directly on HEC-GeoRAS outputs as flood water depth and inundated flood extents, in order to calibrate the model [35].

The model calibration is conducted to find the values of Manning's roughness, by comparing simulated and observed flood water depths and flood water extents at the randomly selected observation points. For each HEC-RAS simulation, [36] the average difference (D) between the observed and simulated flood water depths (m) is computed using Eq. (1).

$$
D=\left[\frac{\sum_{i=1}^{n}\left(d_{o b}-d_{S i}\right)^{2}}{n}\right]^{0.5}
$$

Where $d_{o b}$ and $d_{s i}$ are observed and simulated flood water depth in point $\mathrm{i}$ and $\mathrm{n}$ is the number of point observations. This parameter shows the average vertical distance, over the study reach, and provides an intuitive measure of the accuracy. The significant differences between observed and simulated values are investigated using a paired sample t-test [37]. The criteria to choose the optimal coefficient is reaching to the least differences between simulation and observation points of flood water depth and flooded area.
Some GPS data were observed in the main channel and floodplain for comparing the performance of the model to compute flood water depths table 1 .

Table 1. Simulated and observed flow depth.

\begin{tabular}{llllll}
\hline No & Simulated & Observed & No & Simulated & Observed \\
\hline 1 & 0.01 & 0.42 & 17 & 1.9 & 2.4 \\
2 & 0.02 & 0.46 & 18 & 1.9 & 2.4 \\
3 & 0.09 & 0.52 & 19 & 2 & 2.5 \\
4 & 0.1 & 0.57 & 20 & 2.1 & 2.8 \\
5 & 0.2 & 0.61 & 21 & 2.3 & 3 \\
6 & 0.5 & 0.62 & 22 & 2.4 & 3.1 \\
7 & 0.8 & 1.1 & 23 & 2.4 & 3.2 \\
8 & 0.9 & 1.3 & 24 & 2.4 & 3.3 \\
9 & 1 & 1.4 & 25 & 2.5 & 3.4 \\
10 & 1.2 & 1.5 & 26 & 2.8 & 3.6 \\
11 & 1.5 & 2.1 & 27 & 2.9 & 3.6 \\
12 & 1.5 & 2.2 & 28 & 3.2 & 3.7 \\
13 & 1.5 & 2.2 & 29 & 3.5 & 3.8 \\
14 & 1.5 & 2.3 & 30 & 3.7 & 3.9 \\
15 & 1.6 & 2.3 & 31 & 3.9 & 4.2 \\
16 & 1.8 & 2.4 & 32 & 4.1 & 4.4 \\
\hline
\end{tabular}

Based on trial and error model runs, a Manning's roughness coefficient of 0.035 and 0.045 produced the best fit $\mathrm{D}=0.5806$, against the observed data for the river main channel and floodplain, respectively. As shown in figure 10 the flood water depths from the optimal Manning's $\mathrm{n}$ are in acceptable agreement with those simulated ones with a significant coefficient determination $\left(\mathrm{R}^{2}=0.971\right)$. The result using optimal Manning coefficient, of main channel and floodplain show good correspondence between simulated and observed flood inundated extents and the acceptable delineated floodplain boundary.

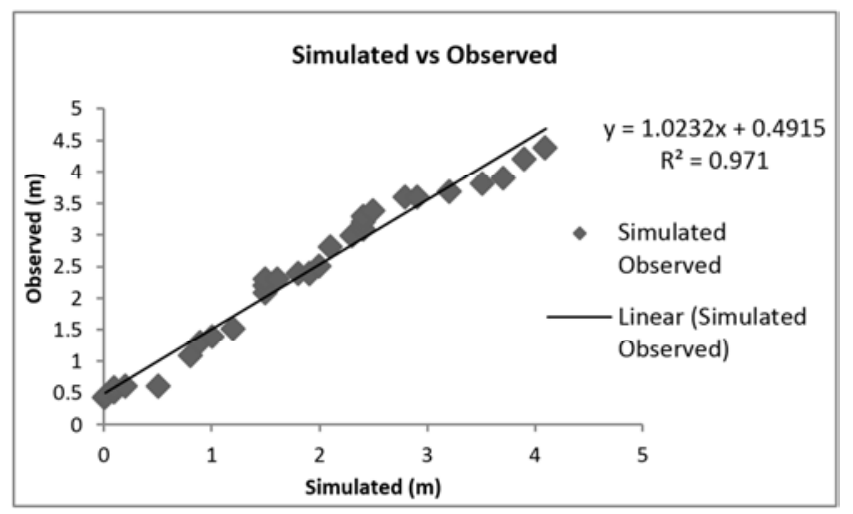

Figure 10. Comparison between observed flood water depth (meter) and simulated depth (meter).

F-statistics equation (2) is defined as the ratio of the area of the overlapping portion of the two flood inundations to the area of both flood inundations projected on the map [35]. It has been consistently used to compare the geospatial similarity of the mapped area over various studies. To evaluate the performance of the model, the F statistic used to compare the drone and HEC-RAS inundation areas [38]

$$
\mathrm{F}=\left[\frac{\mathrm{A}_{\mathrm{OP}}}{\mathrm{A}_{\mathrm{O}}+\mathrm{A}_{\mathrm{P}}-\mathrm{A}_{\mathrm{OP}}}\right] * 100
$$


Where $A_{O}$ indicates the inundation area by asking land owners; $A_{P}$ refers to the predicted flood inundation area and $A_{O P}$ represents the intersection of $A_{O}$ and $A_{P}$. High F-statistics indicates the goodness of fit between simulations and observations. Fstatistic from equation the values varies from "100" when observed and predicted floodplain areas coincide perfectly to " 0 " when there is no overlap between the predicted and observed areas. The overlap area in between the simulated and observed flood plain area has shown F statistics value of $89.80 \%$. This indicates that the simulated result is almost matched with the observed values. Then, it is possible to say that the model approximates the field situation.

\subsection{Flood Inundation Area Delineation Using HEC-GeoRAS}

The Hydrologic Engineering Centre's River Analysis System (HEC-RAS) is well-suited for developing flood inundation delineation and mapping for a variety of applications. Flood inundation delineation has been carried out by using HEC-GeoRAS model in HEC-RAS which is an extension of ArcGIS. HEC_RAS and HEC_GeoRAS can aid in the development of flood inundation maps [39]. Once the HEC-RAS model was complete, output data was exported to
GIS. HEC-GeoRAS was used to compile the data into useful graphical output such as floodplain polygon shape files. To generate floodplain shape files, the GeoRAS extension is used to first create a water surface TIN for each of the flood events. The water surface TIN is automatically clipped to fall within the bounds of the cross sections (i.e., it does not extend beyond the end points of any cross section), and is completely independent of the terrain TIN. After the water surface TIN is created, the rasterazition of the water surface TIN and the terrain TIN takes place and the floodplain is delineated where the water surface exceeds the terrain elevations as show in figure 12. The HEC-RAS model simulations result has been processed by HEC-GeoRAS for flood inundation delineation and hazard map generation. The flooded areas along the Muga River have been mapped based on the exceedence of highest flows for different return periods using the HEC_RAS model. The delineated flood plain area at different return period peak discharges is shown in the figure11. As it is shown in the figure 12. Below the flood plain area coverage are higher at the downstream reach of the river than the upper reach.

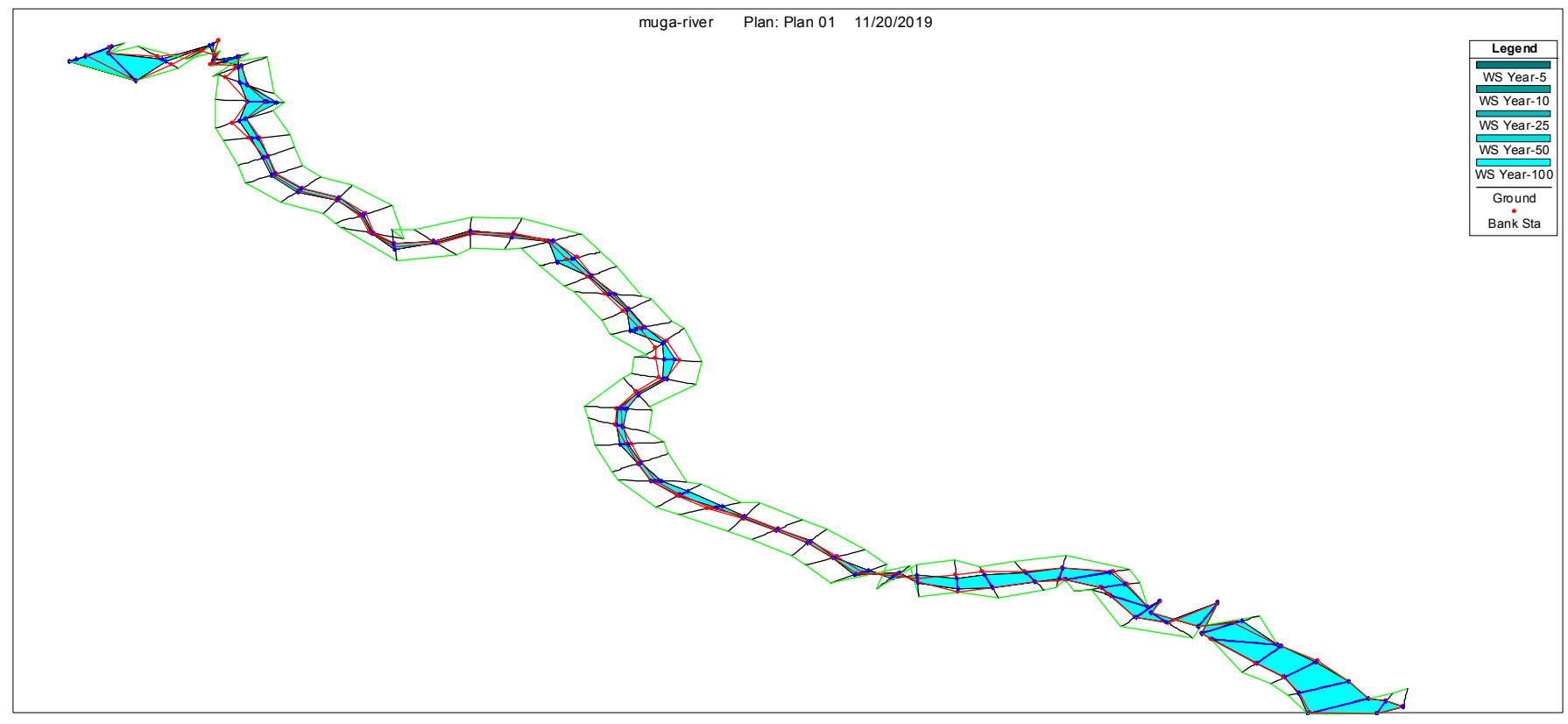

Figure 11. 3D water surface profile of Muga watershed.

\subsection{Flood Plain Mapping}

According to the model results, there is considerable flooding in the area. This implies that the channel capacity is small to carry the floodwater discharge. The areas along the Muga River simulated to be inundated for 5, 10, 25, 50 and 100 years return periods. The flooded areas along the Muga River are $18 \mathrm{~km}^{2}, 21 \mathrm{~km}^{2}, 26 \mathrm{~km}^{2}, 34 \mathrm{~km}^{2}$ and $43 \mathrm{~km}^{2}$ for 5 , $10,25,50$ and 100 year return periods, respectively. On the other hand, the flood inundation area within 100_yrs return period peak discharge covers $1.84 \%$ of Built up area, $43.79 \%$ of Cultivated area, 32.27 of Grass land area and $22.10 \%$ Shrub and Bush land area. The inundation maximum depth within 100 years return period peak flood reaches up to 4.13 $\mathrm{m}$ or 162.23 inch 4 . This indicates that the occurrence of such depth of flood affects agricultural areas and peoples who are living near to the river banks, shows areal extent of 100_yrs return period flood inundation area coverage of nearby kebeles. The flood inundation map indicates a high risk to the agricultural land and river with considerable water depth. These areas are the most flood-prone areas in the river floodplains and need further considerations for flood protection. The ratios of flood affected areas of the nearby kebeles are presented in table 2. As shown in the table the 100_years flood coverage in is Mushiret Dinigay Anibete is 
the highest $(50.7 \%)$ next to the highest one is Werq Amba Berech kebele (20.714\%). This action also should start Google Earth and provide the opening view in floodplain mapping results.

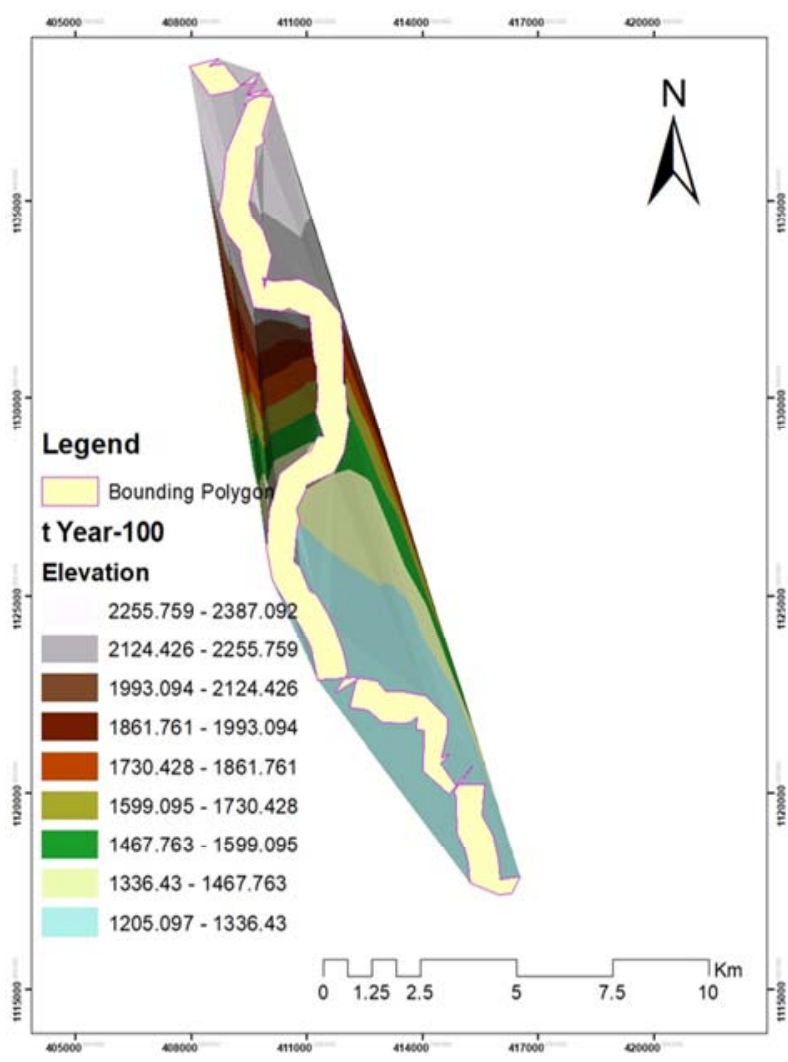

Figure 12. Water surface TIN generated and bounding polygon.

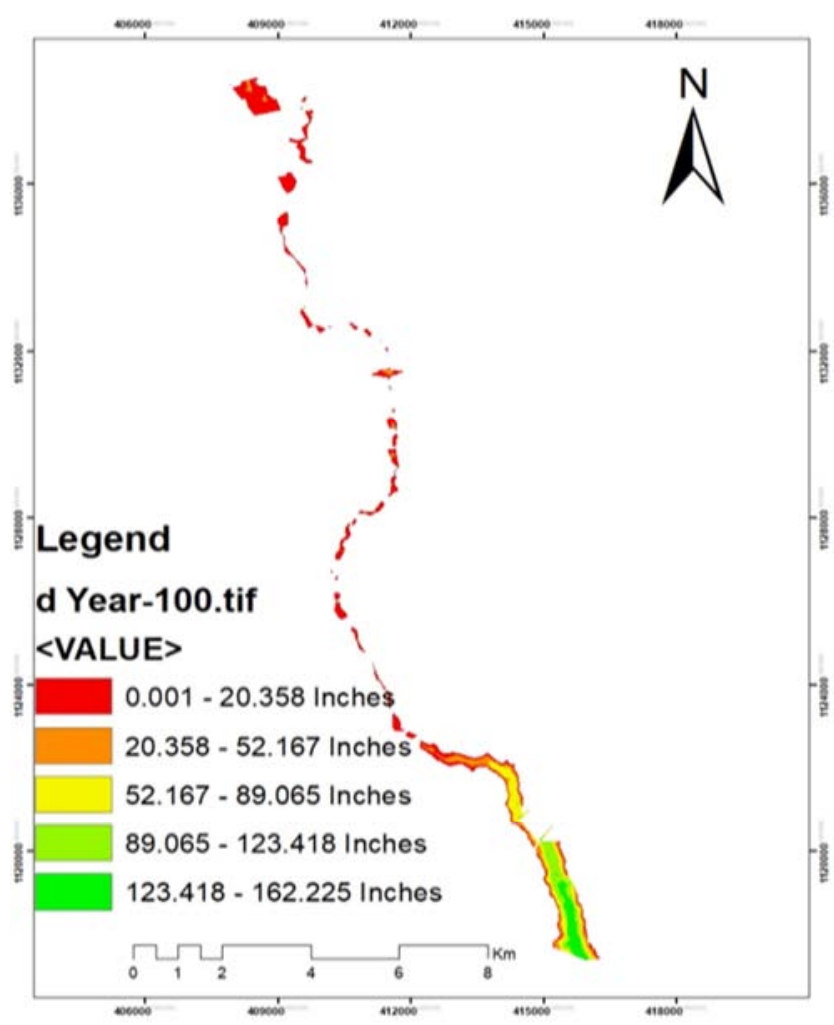

Figure 13. 100-Years return period flood depth.

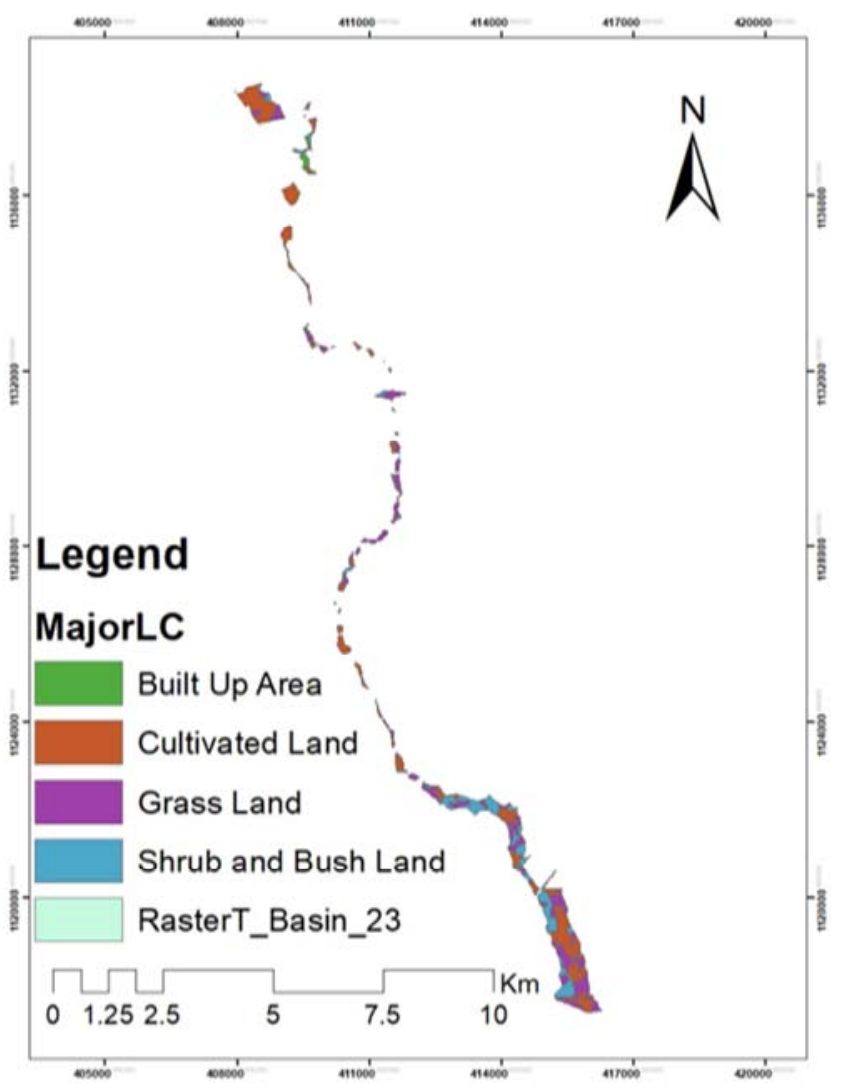

Figure 14. 100-Years return period floodplain coverage extent on the land use and cover.

Table 2. Flood affected kebeles.

\begin{tabular}{lll}
\hline W_Name & Kebele_Name & Present of affected by flood \\
\hline Enemay & Feleg Selam & 0.006 \\
Dejen & Ssb Shengo Alqitam & 2.051 \\
Dejen & Werq Amba Berech & 20.714 \\
Dejen & Hagere Selam Tsidm & 6.239 \\
Dejen & Borebor Shenicha & 0.807 \\
Dejen & Enizigosh & 18.181 \\
Dejen & Mushiret Dinigay Anibete & 50.700 \\
Dejen & Geligele & 1.302 \\
\hline
\end{tabular}

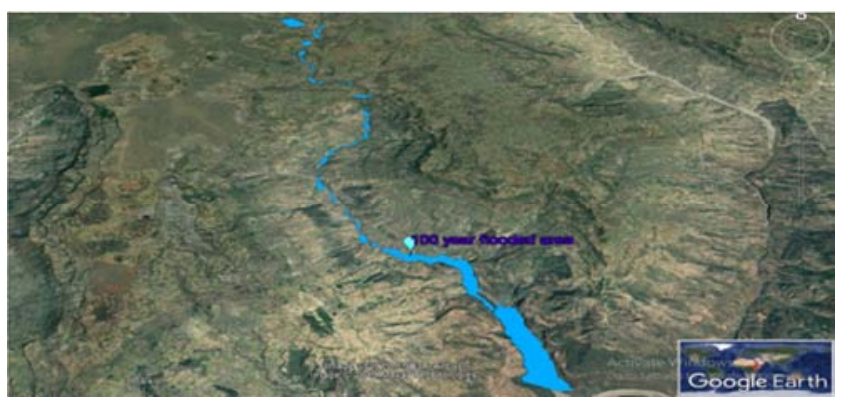

Figure 15. 100 yrs. return period Floodplain area on Google Earth.

\section{Conclusions}

The findings from this study revealed that the integration of hydraulic model and GIS can provide better approximation for flood plain analysis, inundation flood mapping and flood hazard. The flooded areas along the Muga River have been 
delineated based on highest flows for different return periods using the one-dimensional numerical model HEC-RAS, GIS for spatial data processing and HEC-GeoRAS for interfacing between HEC-RAS and GIS. The flood plain areas along the Muga River simulated to be inundated for 5, 10, 25, 50 and 100 years return periods. The flooded areas along the Muga River are $18 \mathrm{~km}^{2}, 21 \mathrm{~km}^{2}, 26 \mathrm{~km}^{2}, 34 \mathrm{~km}^{2}$ and $43 \mathrm{~km}^{2}$ for 5 , $10,25,50$ and 100 year return periods, respectively. The maximum depth of flood with 100-year return period was estimated to be $4.13 \mathrm{~m}$. On the other hand, the percentages of each land covered by flood plain are built up area (1.84\%), cultivated land (43.79\%), Grass land (32.27) and Shrub and Bush land (22.10\%).

The selected flood generating factors were processed to delineate flood hazard zone using multi criteria evaluation techniques in a GIS environment. The weights for very low, low, moderate, high, and very high hazard zone were formulated based on different possible realization as well as from the knowledge of previous studies. The flood hazard assessment indicates that the low-lying areas near the Muga River, particularly in the downstream part are in the high to very high flood hazard zone.

Hence, this methodology will be helpful for preliminary information guide for land use planning, policy makers to provide early warning system information for the preparedness of flood event and investment decision as well as for security reasons.

\section{Acknowledgements}

The authors would like to acknowledge the Ethiopian Ministry of Water, Irrigation and Electricity for proving the flow, soil, and land use/cover data and the National Meteorology Agency of Ethiopia for providing the required rainfall data and stream flow data. We also want to acknowledge Dr. Mulu Sewinet for his professional assistance in language and grammar editing.

\section{References}

[1] Knox JC. Floodplain sedimentation in the Upper Mississippi Valley: Natural versus human accelerated. Geomorphology. 2006; 79(3-4):286-310.

[2] Douglas I, Alam K, Maghenda M, Mcdonnell Y, McLean L, Campbell J. Unjust waters: climate change, flooding and the urban poor in Africa. Environment and urbanization. 2008; 20(1):187-205.

[3] Baker C, Thompson JR, Simpson M. Hydrological dynamics I: surface waters, flood and sediment dynamics. The wetlands handbook. 2009; 2:120-68.

[4] Moges S, Alemu Y, McFeeters S, Legesse W. Flooding in Ethiopia. Water resources management in Ethiopia: Implications for the Nile Basin. 2010;285.

[5] Fohringer J, Dransch D, Kreibich H, Schröter K. Social media as an information source for rapid flood inundation mapping. Natural Hazards and Earth System Sciences (NHESS).

\section{$2015 ; 15: 2725-38$}

[6] Glade T, Crozier MJ. Landslide hazard and risk: concluding comment and perspectives. Landslide hazard and risk Wiley, Chichester. 2005:767-74.

[7] Mohd MS, Alias B, Daud D, editors. GIS analysis for flood hazard mapping: Case study Segamat, Johor, West Malaysia. Seminar Nasional GIS; 2006.

[8] Akbari A, Ramli NIB, Kong NS. Application of public domain satellite-based DEMs in natural hazard modeling. International Journal of Environmental Science and Development. 2016;7(2):140.

[9] Kourgialas NN, Karatzas GP. Flood management and a GIS modelling method to assess flood-hazard areas - a case study. Hydrological Sciences Journal-Journal des Sciences Hydrologiques. 2011;56(2):212-25.

[10] Merz B, Kreibich H, Schwarze R, Thieken A. Review article'Assessment of economic flood damage'. Natural Hazards and Earth System Sciences (NHESS). 2010;10(8):1697-724.

[11] Quintana XD, Moreno-Amich R, Comin FA. Nutrient and plankton dynamics in a Mediterranean salt marsh dominated by incidents of flooding. Part 1: Differential confinement of nutrients. Journal of Plankton research. 1998;20(11):2089-107.

[12] Dutta NM. Impact of flood and soil erosion on the socioeconomic and demographic characteristics of Majuli Island 2009.

[13] Ilorme F. Flood Risk Assessment in Haiti Using Remote Sensing and Geographic Information Systems: Michigan Technological University; 2007.

[14] Lester PM. On floods and photo ops: How Herbert Hoover and George W. Bush exploited catastrophes: Univ. Press of Mississippi; 2010.

[15] Upadhyaya JK, Biswas N, Tam E. A review of infrastructure challenges: Assessing stormwater system sustainability. Canadian Journal of Civil Engineering. 2014;41(6):483-92.

[16] Billi P, Alemu YT, Ciampalini R. Increased frequency of flash floods in Dire Dawa, Ethiopia: Change in rainfall intensity or human impact? Natural Hazards. 2015;76(2):1373-94.

[17] Mirza MMQ. Climate change, flooding in South Asia and implications. Regional environmental change. 2011;11(1):95107.

[18] Thakur B, Parajuli R, Kalra A, Ahmad S, Gupta R, editors. Coupling HEC-RAS and HEC-HMS in precipitation runoff modelling and evaluating flood plain inundation map. World Environmental and Water Resources Congress 2017; 2017.

[19] TEGNIE EB. FLOODPLAIN MAPPING AND MODELING FOR GERAY RIVER: ADDIS ABABA SCIENCE AND TECHNOLOGY UNIVERSITY; 2018.

[20] Jamil M, Sahana M, Sajjad H. Crop suitability analysis in the Bijnor District, UP, using geospatial tools and fuzzy analytical hierarchy process. Agricultural Research. 2018;7(4):506-22.

[21] Merwade V. Tutorial on using HEC-GeoRAS with ArcGIS 10 and HEC-RAS Modeling. School of Civil Engineering, Purdue University. 2012. 
[22] Sharkey JK. Investigating Instabilities with HEC-RAS Unsteady Flow Modeling for Regulated Rivers at Low Flow Stages. 2014.

[23] Madadi MR, Azamathulla HM, Yakhkeshi M. Application of Google earth to investigate the change of flood inundation area due to flood detention dam. Earth Science Informatics. 2015;8(3):627-38.

[24] Rahmati O, Zeinivand H, Besharat M. Flood hazard zoning in Yasooj region, Iran, using GIS and multi-criteria decision analysis. Geomatics, Natural Hazards and Risk. 2016;7(3):1000-17.

[25] Abera Z. Flood Mapping and Modeling on Fogera Flood Plain A Cas e Study of Ribb River. Addis Ababa Institute of Technology. 2011.

[26] Pathan AI, Agnihotri P. A combined approach for 1-D hydrodynamic flood modeling by using Arc-Gis, Hec-Georas, Hec-Ras Interface-a case study on Purna River of Navsari City, Gujarat. IJRTE. 2019;8(1):1410-7.

[27] Kardavani P, Qalehe MH. Efficiency of Hydraulic Models for Flood Zoning Using GIS (Case Study: Ay-Doghmush River Basin). Life Science Journal. 2013;10(2).

[28] YS G, Gebre S. Civil \& Environmental Engineering. 2015.

[29] Jensen MR, Lowney CL. Temperature modeling with HECRAS. Critical Transitions in Water and Environmental Resources Management2004. p. 1-10.

[30] Patel SB, Mehta DJ, Yadav SM. One dimensional hydrodynamic flood modeling for Ambica River, South Gujarat. Journal of Emerging Technologies and Innovative Research. 2018;5(4):595-601.

[31] Kordi E, Ayyoubzadeh S, Ahmadi M, Zahiri A. Prediction of the lateral flow regime and critical depth in compound open channels. Canadian Journal of Civil Engineering. 2009;36(1):1-13.

[32] Qasim JM. Laboratory and HEC-RAS simulations of a singlestep weir. ARPN Journal of Engineering and Applied Sciences. 2013;8(12):1005-11.

[33] Rubiu F. Flood risk assessment in the vicinity of kartena town using hec-ras 1d-2d models: Aleksandras Stulginskis University; 2018.

[34] Pike AS, Scatena FN. Riparian indicators of flow frequency in a tropical montane stream network. Journal of hydrology. 2010;382(1-4):72-87.

[35] Renschler CS, Wang Z. Multi-source data fusion and modeling to assess and communicate complex flood dynamics to support decision-making for downstream areas of dams: The 2011 hurricane irene and schoharie creek floods, NY. International journal of applied earth observation and geoinformation. 2017;62:157-73.

[36] Quirogaa VM, Kurea S, Udoa K, Manoa A. Application of 2D numerical simulation for the analysis of the February 2014 Bolivian Amazonia flood: Application of the new HEC-RAS version 5. Ribagua. 2016;3(1):25-33.

[37] Georgopoulos A, Massey J. Cognitive spatial-motor processes. Experimental Brain Research. 1988;69(2):315-26.

[38] Yalcin E. Assessing the impact of topography and land cover data resolutions on two-dimensional HEC-RAS hydrodynamic model simulations for urban flood hazard analysis. Natural Hazards. 2020:1-23.

[39] Zope P, Eldho T, Jothiprakash V. Impacts of urbanization on flooding of a coastal urban catchment: a case study of Mumbai City, India. Natural Hazards. 2015;75(1):887-908. 